\title{
Efektivitas Cangkang Hama Bekicot (Achatina fulica) Sebagai Adsorben Untuk Meningkatkan Kualitas Air Sungai Kahayan
}

\author{
Achmad Imam Santoso ${ }^{1 *}$, Dhymas Sulistyono Putro ${ }^{2}$ \\ 1,2Environmental Engineering, Faculty of Engineering and Informatics, Universitas Muhammadiyah Palangkaraya \\ *Koresponden email: achmad_imam28@yahoo.com
}

Diterima: 30 September 2020

Disetujui: 15 Oktober 2020

\begin{abstract}
The water quality of the Kahayan River is still below the criteria for clean water quality standards. One of the treatments to improve water quality is snail shells as adsorbents of heavy metals Fe and $\mathrm{Zn}$ are categorized as pests on fruit plants. The object of this research is the snail shell activated charcoal is used to improve the quality of river water on heavy metals $\mathrm{Fe}$ and $\mathrm{Zn}$. The mass variation of snail shell activated charcoal weighing 0 grams, 5 grams, 10 grams, and 15 grams. The research process is divided into the Preparation Stage and Implementation Stage, where the implementation stage consists of making snail shell charcoal, making $\mathrm{HCl}$ solution, activating snail shell charcoal, and absorbing snail shell activated charcoal. Snail shell activated charcoal plays an active role in decreasing Fe and $\mathrm{Zn}$ concentrations. At $5 \mathrm{mg}$ of snail shell activated charcoal was able to reduce $53 \% \mathrm{Fe}$ concentration and $69 \% \mathrm{Zn}$ concentration. Snail shell activated charcoal with a mass of $10 \mathrm{mg}$ and $15 \mathrm{mg}$ was able to reduce Fe concentration by $82 \%$ and $84 \%$. Testing the $\mathrm{Zn}$ concentration in the mass of $10 \mathrm{mg}$ and $15 \mathrm{mg}$ was not read optically, due to the limited accuracy of laboratory equipment.
\end{abstract}

Keywords: activated charcoal, snail, Fe, water quality, Zn.

\begin{abstract}
Abstrak
Kualitas air bersih Sungai Kahayan masih berada dibawah kriteria baku mutu air bersih. Adanya Fe dan $\mathrm{Zn}$ terkandung dalam air akan menyebabkan gangguan kesehatan pada masyarakat yang menggunakannya. Salah satu pengolahan untuk meningkatkan kualitas air yaitu dengan menggunakan cangkang bekicot sebagai adsorben logam berat $\mathrm{Fe}$ dan $\mathrm{Zn}$ yang dikategorikan sebagai hama pada tanaman buah. Objek penelitian ini adalah arang aktif cangkang bekicot yang digunakan dalam meningkatkan kualitas air Sungai pada logam berat Fe dan Zn. Variasi massa dari arang aktif cangkang bekicot seberat 0 gram, 5 gram, 10 gram dan 15 gram. Proses penelitian ini terbagi atas Tahap Persiapan dan Tahap Pelaksanaan, dimana Tahap Pelaksanaan terdiri atas Pembuatan arang cangkang bekicot, Pembuatan larutan $\mathrm{HCl}$, Pengaktifan arang cangkang bekicot, dan Absorpsi arang aktif cangkang bekicot. Arang aktif cangkang bekicot berperan aktif dalam penurunan konsentrasi Fe dan Zn. Pada 5 mg arang aktif cangkang bekicot mampu menurunkan 53\% konsentrasi Fe dan 69\% konsentrasi Zn. Arang aktif cangkang bekicot dengan massa $10 \mathrm{mg}$ dan $15 \mathrm{mg}$ mampu menurunkan konsentrasi Fe sebanyak $82 \%$ dan $84 \%$. Pengujian konsentrasi $\mathrm{Zn}$ pada massa $10 \mathrm{mg}$ dan $15 \mathrm{mg}$ tidak terbaca secara optimal, dikarenakan keterbatasan ketelitian alat laboratorium.
\end{abstract}

Kata Kunci: arang aktif, bekicot, Fe, kualitas air, Zn.

\section{Pendahuluan}

Rata-rata kebutuhan air bersih masyarakat di Indonesia adalah 60 liter per kapita per hari [1]. Menurut [2] air bersih dapat diperoleh dari berbagai sumber, seperti air hujan (rain water), air permukaan (surface water), air tanah (ground water), dan air laut (sea water). Air tersebut tidak dapat langsung dimanfaatkan, sehingga perlu dilakukan pengolahan terlebih dahulu.

Palangka Raya merupakan salah satu kota yang dilalui oleh Daerah Aliran Sungai (DAS) Sungai Kahayan, dimana masyarakat yang mendiami sekitar DAS Sungai Kahayan menggunakan air sungai untuk memenuhi kebutuhan sehari-hari. Kualitas air bersih Sungai Kahayan masih berada dibawah ambang batas baku mutu yang telah ditetapkan oleh [3]. Hal ini terlihat dari penelitian yang dilakukan oleh [4] bahwa parameter Fe dan Zn berada dibawah ambang batas baku mutu. Adanya Fe dan Zn yang terkandung dalam air akan menyebabkan gangguan kesehatan pada masyarakat yang menggunakannya. Gangguan kesehatan yang terjadi pada sistem pencernaan dan kulit [5]. Fe dan Zn yang terserap oleh tanah akan menyebabkan penurunan tingkat kesuburan tanah dan tumbuhan yang ada memiliki konsentrasi Fe dan Zn yang tinggi [6]. 
Pengolahan air Sungai Kahayan perlu dilakukan, seiring tingginya penggunaan sumber air Sungai Kahayan oleh masyarakat, dimana terlihat banyaknya masyarakat yang bermukim di tepi Sungai Kahayan [7][8]. Salah satu pengolahan untuk meningkatkan kualitas air yaitu hama cangkang bekicot sebagai adsorben logam berat $\mathrm{Fe}$ dan $\mathrm{Zn}$ [9] [10]. Bekicot mudah ditemui pada daerah dengan kelembaban yang tinggi, sehingga memudahkan pelaksanaan penelitian ini [11] dan dikategorikan sebagai hama pada tanaman buah [12]. Adanya penelitian akan meningkatkan ketersediaan air bersih serta menurunkan populasi bekicot sebagai hama tanaman buah.

\section{Metodologi Penelitian}

\section{Lokasi, Waktu, dan Objek Penelitian}

Penelitian dilakukan di Laboratorium Fakultas Teknik UM Palangkaraya untuk pengujian Laboratorium dilakukan oleh Laboratorium Kesehatan Daerah Palangka Raya. Pengambilan sampel dilaksanakan pada 5 Mei 2020, sedangkan pengujian sampel dilaksanakan pada 14 Mei 2020. Objek penelitian ini adalah pengolahan hama yaitu bekicot untuk pengolahan air Sungai Kahayan menjadi air bersih.

\section{Metode Penelitian}

Penelitian ini terdiri atas dua variable yaitu variable bebas dan variable terikat. Variabel bebas terdiri dari atas 4 masa bekicot, yaitu 0 gram (kontrol), 5 gram, 10 gram dan 15 gram. Sementara variable terikat terdiri atas 2, yaitu konsentrasi $\mathrm{Fe}$ dan $\mathrm{Zn}$.

\section{Prosedur}

\section{a. Pembuatan arang cangkang bekicot}

Cangkang dibersihkan menggunakan air bersih agar terhindar dari kotoran, selanjutnya cangkang bekicot dijemur hingga air sisa pembersihan menghilang. Setelah cangkang bekicot mengering, dilakukan sangrai hingga menjadi arang dengan estimasi waktu \pm 30 menit. Arang yang telah disangrai, dihancurkan hingga menjadi partikel yang lebih kecil. Kemudian dilakukan pengayakan agar memperoleh ukuran partikel yang seragam. Arang dengan partikel seragam dimasukkan oven selama 1 jam, sehingga menurunkan kandungan air.

\section{b. Pembuatan larutan $\mathrm{HCl}$}

Langkah pertama yaitu menentukan konsentrasi menggunakan persamaan:

$$
\mathrm{N}=((10 \times \% \mathrm{x} \text { berat jenis }) \times \text { valensi }) / \mathrm{BM}
$$

maka akan ditemukan konsentrasi $\mathrm{HCl}$ sebesar $83 \mathrm{~mL}$. Kemudian larutan $\mathrm{HCl}$ dipindahkan ke wadah lain untuk dilakukan pencampuran terhadap arang cangkang bekicot.

\section{c. Pengaktifan arang cangkang bekicot}

Pengaktifan arang cangkang bekicot melibatkan arang dan larutan $\mathrm{HCl}$. Arang dimasukkan ke wadah pengaktifan yang telah berisi cairan $\mathrm{HCl}$, lalu didiamkan selama 24 jam. Setelah 24 jam, dilakukan penyaringan untuk memisahkan arang terhadap larutan $\mathrm{HCl}$. Arang yang telah disaring dimasukkan ke dalam oven untuk menguapkan air serta $\mathrm{HCl}$ yang terkandung. Setelah 1 jam didalam oven, arang telah aktif dan siap untuk proses absorpsi.

\section{d. Adsorbsi Arang Aktif bekicot}

Proses ini membutuhkan Jar Test dan beaker glass. Sampel air Sungai Kahayan dimasukkan pada keenam beaker glass dengan masing-masing dengan massa $500 \mathrm{~mL}$. Selanjutnya, arang aktif akan dibedakan menjadi tiga perlakuan dengan massa 5 gram, 10 gram, dan 15 gram dimana masing-masing perlakuan terbagi atas dua beaker glass. Pengadukan menggunakan jar test dilakukan selama \pm 15 menit pada seluruh perlakuan. Setelah pengadukan, perlakuan didiamkan hingga terjadi pengendapan. Air hasil pengendapan pada masing-masing perlakuan diuji laboratorium untuk mengetahui konsentrasi $\mathrm{Fe}$ dan Zn.

\section{Hasil dan Pembahasan \\ Kualitas Air Sungai Kahayan}

Sampel diambil di Sungai Kahayan sampel diambil di sekitar jembatan Kahayan pada titik koordinat $2^{\circ} 12^{\prime} 09.9^{\prime \prime S} 113^{\circ} 55^{\prime} 15.7^{\prime \prime E}$. Hasil Uji Laboratorium dapat dilihat pada Tabel 1. 


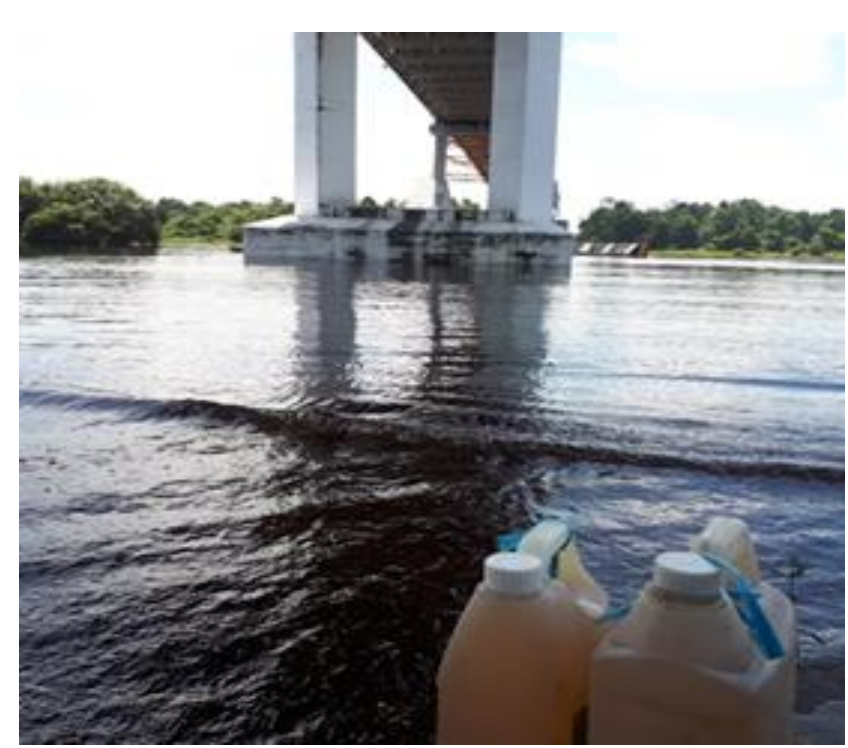

Gambar 1. Lokasi pengambilan sampel

Sumber: Data primer, 2020

Tabel 1. Hasil uji laboratorium air Sungai Kahayan

\begin{tabular}{llll}
\hline Parameter & Satuan & Hasil Pengujian & Spesifikasi metode \\
\hline Besi $(\mathrm{Fe})$ & $\mathrm{mg} / \mathrm{L}$ & 0.270 & SNI 6989.4:2009 \\
Seng $(\mathrm{Zn})$ & $\mathrm{mg} / \mathrm{L}$ & 0.013 & SNI 6989.7:2009 \\
\hline
\end{tabular}

Sumber: Hasil pengujian, 2020

Dapat dilihat pada Tabel 1 air di sungai Kahayan mengandung Fe sebesar 0,27 mg/L dan Zn sebesar 0,013 mg/L. Baku mutu lingkungan PP 82 Tahun 2001 menyatakan air Sungai Kahayan dikategorikan kriteria air bersih kelas 1 berdasarkan parameter Fe dan Zn. Sehingga air Sungai Kahayan mampu digunakan dalam memenuhi kebutuhan sehari-hari masyarakat.

\section{Hasil Uji Kandungan Fe dan Zn}

Air Sungai Kahayan yang telah dikontakkan terhadap arang aktif dari cangkang bekicot dan $\mathrm{HCl}$ dengan metode Jar Test dimasukan ke Laboratorium Kesehatan Daerah Palangka Raya. Hasil dari uji laboratorium kandungan $\mathrm{Fe}$ dan $\mathrm{Zn}$ terjadi penurunan setelah dilakukan pengolahan dengan arang dari cangkang bekicot. Hasil pengujian laboratorium Kesehatan Daerah Palangkaraya dapat dilihat pada Tabel 2.

Tabel 2. Hasil uji laboratorium

\begin{tabular}{cccc}
\hline \multirow{2}{*}{ Nama Sampel } & Satuan & \multicolumn{2}{c}{ Hasil Pengujian } \\
\cline { 3 - 4 } & & Besi (Fe) & Seng (Zn) \\
\hline $\mathrm{X}$ & $\mathrm{mg} / \mathrm{L}$ & 0,270 & 0,042 \\
$\mathrm{~A}$ & $\mathrm{mg} / \mathrm{L}$ & 0,125 & 0,013 \\
$\mathrm{~B}$ & $\mathrm{mg} / \mathrm{L}$ & 0,048 & $<0,002$ \\
$\mathrm{C}$ & $\mathrm{mg} / \mathrm{L}$ & 0,042 & $<0,002$ \\
\hline \multicolumn{3}{c}{ Sumber: Hasil pengujian, 2020 }
\end{tabular}

\section{Efektivitas Arang Cangkang Bekicot dalam Penurunan konsentrasi Besi (Fe)}

Penurunan konsentrasi Fe dari awal tanpa pengolahan pada sampel $X$ sebanyak $0,27 \mathrm{mg} / \mathrm{L}$ yang kemudian setelah dilakukan Jar Test dengan arang aktif cangkang bekicot dari sampel A hingga sampel $\mathrm{C}$ tingkat penurunan konsentrasi Fe pada Gambar 2. 


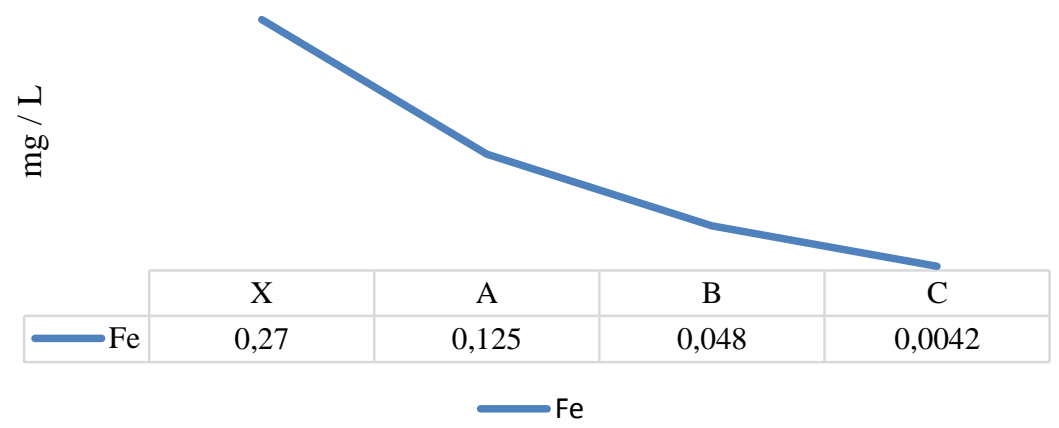

Gambar 2. Penurunan konsentrasi Fe

Sumber: Hasil analisis, 2020

Konsentrasi $\mathrm{Fe}$ yang sebelum pengolahan $0,27 \mathrm{mg} / \mathrm{L}$ setelah dikontakan dengan arang cangkang bekicot sebanyak $5 \mathrm{mg}$ terjadi penurunan konsentrasi $\mathrm{Fe}$ menjadi $0,125 \mathrm{mg} / \mathrm{L}$ penurunan konsentrasi $\mathrm{F}$ sebesar 53\%. Pada pengontakan air Sungai Kahayan dengan arang cangkang bekicot sebanyak $10 \mathrm{mg}$ terjadi penurunan konsentrasi Fe menjadi $0,048 \mathrm{mg} / \mathrm{L}$ penurunan konsentrasi Fe sebesar $82 \%$ dan pada cangkang bekicot $15 \mathrm{mg}$ terjadi penurunan yang tidak terlalu jauh sebesar $84 \%$. Penurunan konsentrasi Fe dalam air disebabkan adanya arang aktif yang mampu menyerap $\mathrm{Fe}$, sehingga semakin tinggi konsentrasi cangkang bekicot yang dicampurkan, maka akan menurunkan konsentrasi Fe dalam air [13] [14]. Persentase tingkat penurunan konsentrasi Fe dapat dilihat pada Gambar 3.

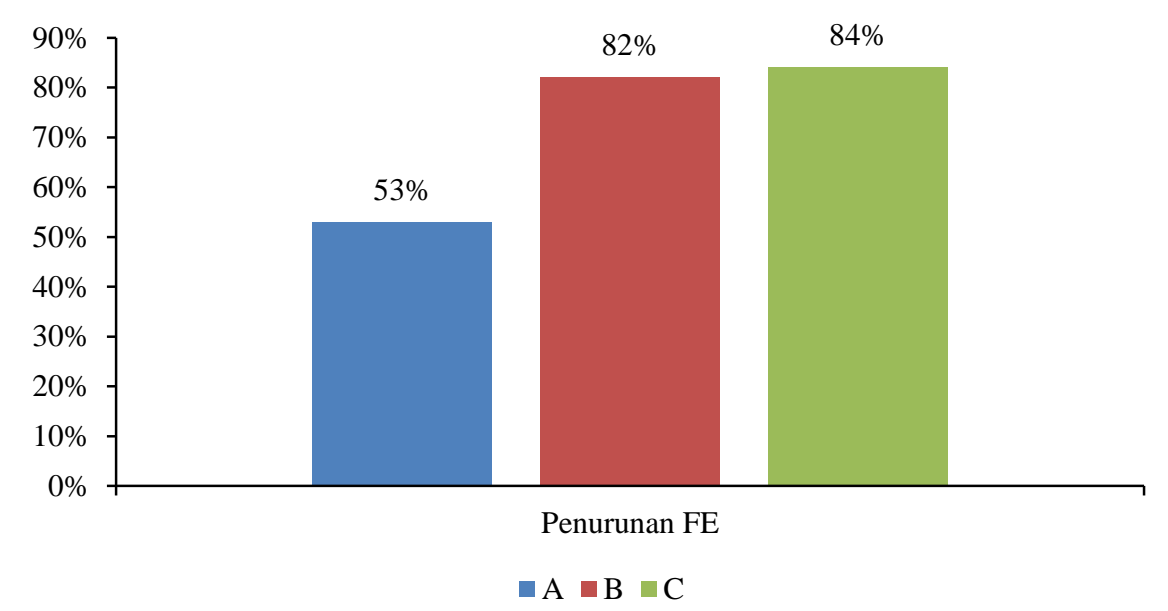

Gambar 3. Persentase penurunan konsentrasi Fe Sumber: Hasil analisis, 2020

\section{Efektivitas Arang Cangkang Bekicot dalam Penurunan Konsentrasi Zn}

Penurunan konsentrasi Zn dari awal tanpa pengolahan pada sampel X sebanyak 0,042 mg/L yang kemudian setelah dilakukan Jar Test dengan arang aktif cangkang bekicot dari sampel A hingga sampel $\mathrm{C}$ tingkat penurunan konsentrasi Zn pada Gambar 4. Konsentrasi Zn sebelum pengolahan 0,042 mg/L, setelah dikontakkan dengan arang aktif cangkang bekicot sebanyak $5 \mathrm{mg}$ terjadi penurunan konsentrasi $\mathrm{Zn}$ menjadi 0,013 mg/L, sedangkan pada pengontakan air Sungai Kahayan dengan arang aktif cangkang bekicot sebanyak $10 \mathrm{mg}$ dan $15 \mathrm{mg}$ penurunan konsentrasi Zn menjadi $<0,002 \mathrm{mg} / \mathrm{L}$. 


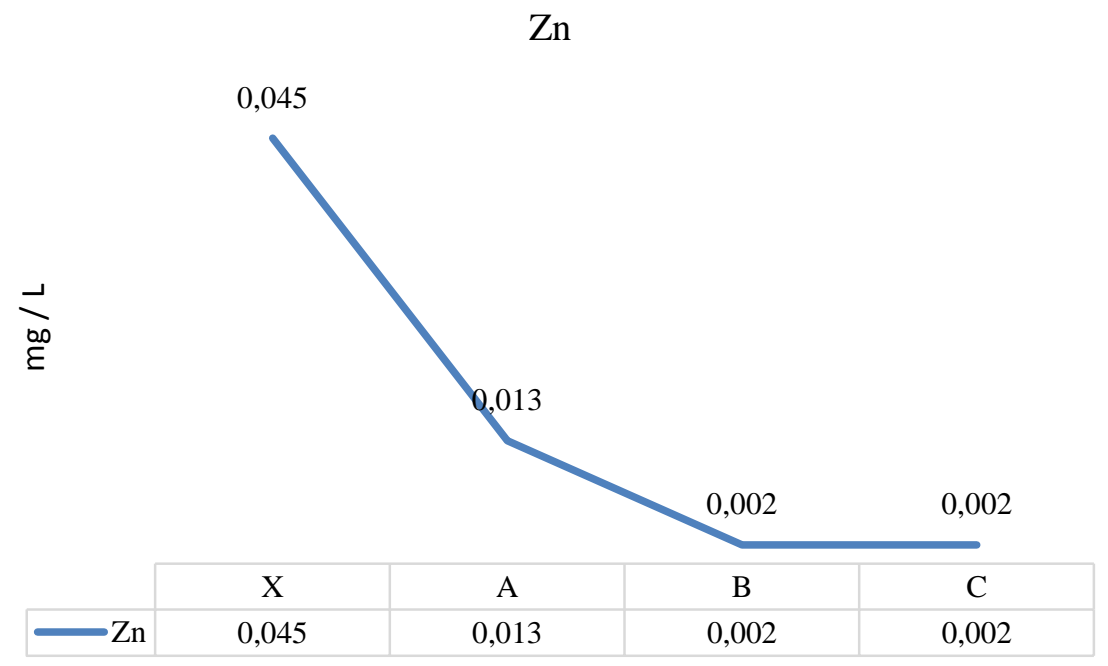

Gambar 4. Penurunan konsentrasi Zn

Sumber: Hasil analisis, 2020

Efektivitas arang aktif cangkang hama bekicot dalam menurunkan konsentrasi $\mathrm{Zn}$ tertulis dalam bentuk persentase. Efektivitas penurunan Tingkat Penurunan konsentrasi Zn pada sungai Kahayan pada Gambar 5.

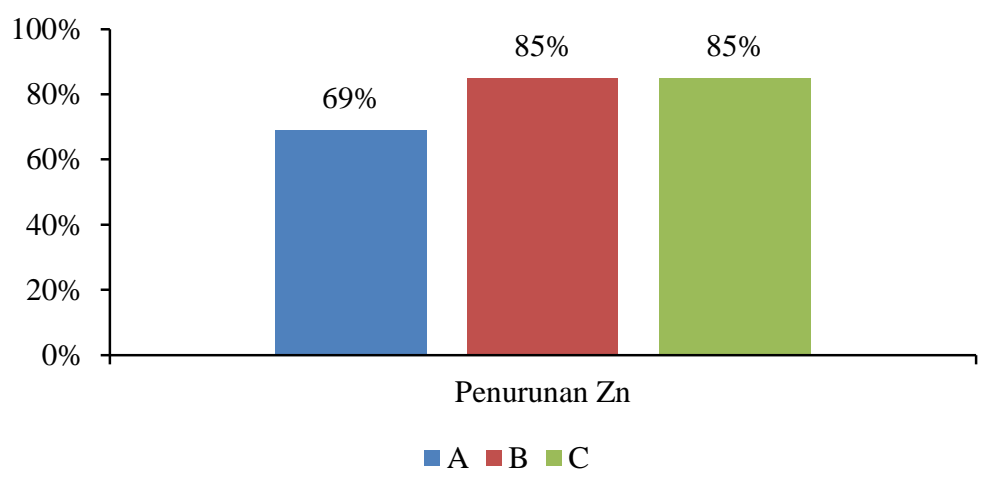

Gambar 5. Persentase penurunan konsentrasi Seng (Zn)

Sumber: Hasil analisis, 2020

Efektivitas penurunan konsentrasi $\mathrm{Zn}$ pada arang aktif cangkang bekicot sebanyak $5 \mathrm{mg}$ yaitu 69\%. Penurunan konsentrasi $\mathrm{Zn}$ sebesar $85 \%$ terjadi pada arang aktif cangkang bekicot sebanyak $10 \mathrm{mg}$ dan $15 \mathrm{mg}$. Konsentrasi $\mathrm{Zn}$ juga mengalami penurunan, dikarenakan cangkang bekicot mampu menyerap Zn yang terkandung dalam air Sungai [15] [16] [17].

\section{Kesimpulan}

Kualitas air Sungai Kahayan pada Jembatan Kahayan pada titik koordinat $2^{\circ} 12^{\prime} 09.9^{\prime \prime S}$ 113 55'15.7"E berdasarkan baku mutu lingkungan PP 82 tahun 2001 pada konsentrasi Besi (Fe) sebesar $0.27 \mathrm{mg} / \mathrm{L}$ dan Seng $(\mathrm{Zn})$ sebesar $0.042 \mathrm{mg} / \mathrm{L}$ dikategorikan kriteria air bersih kelas 1 . Arang aktif cangkang bekicot berperan aktif dalam penurunan konsentrasi Fe dan Zn. Pada $5 \mathrm{mg}$ arang aktif cangkang bekicot mampu menurunkan 53\% konsentrasi Fe dan 69\% konsentrasi Zn. Arang aktif cangkang bekicot dengan massa $10 \mathrm{mg}$ dan $15 \mathrm{mg}$ mampu menurunkan konsentrasi Fe sebanyak 82\% dan 84\%. Pengujian konsentrasi $\mathrm{Zn}$ pada massa $10 \mathrm{mg}$ dan $15 \mathrm{mg}$ tidak terbaca secara optimal, dikarenakan keterbatasan ketelitian alat laboratorium.

\section{Ucapan Terima Kasih}

Author mengucapkan terima kasih kepada Universitas Muhammadiyah Palangka Raya yang telah memberikan bantuan penelitian dalam bentuk dana penelitian serta seluruh pihak yang terlibat dalam jalannya penelitian. 


\section{Referensi}

[1] Junaedi, "Pertumbuhan Bakteri Pada Air Minum Dalam Kemasan Galon Isi Ulang Merk Zammin Pada Tingkat Konsumen Dengan Praktik Higiene Yang Berbeda Di kelurahan Tembalang Kota Semarang," Undip Press, Semarang, 2004.

[2] S. Tjutju, "Air Sebagai Sumber Kehidupan," Oseana, Vol. 23 No. 3 17-25. LIPI, 2003.

[3] Pemerintah Republik Indonesia, Peraturan Pemerintah No. 82 Tahun 2001 Tentang Pengelolaan Kualitas Air Dan Pengendalian Pencemaran Air, 2001.

[4] H. Edison, "Akumulasi Logam Berat Dan Efeknya Terhadap Morfologi Tulang Sirip Keras Ikan Sembilang (Plotosus Canius Web \& Bia) Di Muara Sungai Kahayan Dan Katingan, Kalimantan Tengah," J. Ilmu Hewani Tropika, Vol. 01 No. 02, 2012.

[5] Supratini, "Pengaruh Limbah Industri Terhadap Lingkungan di Indonesia," Media Litbang Kesehatan, Vol. 12 No. 02, 2002.

[6] Mulyaningsih, Th Rina, "Kandungan Unsur Fe Dan Zn Dalam Bahan Pangan Produk Pertanian, Peternakan Dan Perikanan Dengan Metode k0-AANI," J. Sains dan Teknologi Nuklir Indonesia, Vol. 10 No. 02. DOI, 2009.

[7] H. Noor, "Model Permukiman Kawasan Tepian Sungai Kasus: Permukiman Tepian Sungai Kahayan Kota Palangkaraya," J. Permukiman, Vol. 9 No.01, 2014.

[8] S. Rezha, Rusdiansyah, A. Prasetia, dan Hafiizh, "Identifikasi Kualitas Perairan Di Sungai Kahayan Dari Keberadaan Sistem Keramba Studi Kasus Sungai Kahayan Kecamatan Pahandut Kalimantan Tengah," Info Teknik, Vol. 13 No. 02, 2012.

[9] M. Sikana, Arina, F. Ningsih, Nur, R. Saputri, Miftahul, A.T. Wandani, Shelly, dan R. Ambarwati, "Pemanfaatan Limbah Cangkang Kupang Sebagai Sumber Kitin dan Kitosan," J. Sains dan Matematika, Vol. 04 No. 022016, 2016.

[10] I. La, A.M. Awalul, K. Karim, dan A. Andi, "Pengaruh Penambahan Volume Kitosan dari Cangkang Bekicot terhadap Penurunan Kadar Tembaga Air Lindi," J. Teknik (Media Pengembangan Ilmu dan Aplikasi Teknik), Vol. 18 No. 02, 2019.

[11] Muhamat, "Diversitas Bekicot di Kota Banjarbaru Kalimantan Selatan," J. Ilmu-Ilmu Biologi (BIOSCIENTIAE), Vol. 06 No. 02, 2009.

[12] Sari, D. Ekawati, W. Samri, M. Iin, Masruhing, dan Baharuddin, "Inventarisasi Hama Dan Penyakit Tanaman Di Lokasi Budidaya Tanaman Buah Naga Kabupaten Sinjai," Agrominansia, Vol. 04 No. 02, 2020.

[13] Manalu, N. Kresentia, P. Dimas, Widodo, dan L. Urip, "Adsorpsi Logam Fe Dalam Minyak Nilam Menggunakan Kitosan Sisik Ikan,” J. Teknik Kimia, Vol. 14 No. 01, 2019.

[14] H. Cahyono, S. Stefanus, Suganal, Hidayat, dan N. Kukuh, "Perbandingan Koagulan Hasil Percobaan Dengan Koagulan Komersial Menggunakan Metode Jar Test," J. Teknologi Mineral dan Batubara, Vol. 14, No. 01, 2018.

[15] V.M. Stevano, A. Bayu, Syauqiah, dan Isna, "Pemanfaatan Kitosan Dari Limbah Cangkang Bekicot (Achatina fulica) Sebagai Adsorben Logam Berat Seng (Zn)," Konversi, Vol. 5 No. 1, 2016.

[16] Trimaily, D. Nofrizal, dan M. Esy, "Efektivitas Penggunaan Tawas dan Tanah Lempung pada Pengolahan Air Gambut Menjadi Air Bersih," Dinamika Lingkungan Indonesia, Vol. 04 No. 01, 2017.

[17] H. Netty, "Pengaruh Penambahan Tawas dan Kapur Terhadap Kecepatan Pengendapan Air Rawa," Berkala Teknik, Vol.05 No. 02, 2015. 